ZUMJ-1908-1416 (R1)

DOI

10.21608/zumj.2019.15804.1416

ORIGINAL ARTICLE

\title{
Serum Kisspeptin Level in Normal Pregnancy and Preeclampsia With and Without Obesity
}

Ali Khalil Ali Asalah, Professor of Medical Physiology, Faculty of medicine, Zagazig University. Mohamed Abd Elhamed M. El-Sayed, Professor of Medical Physiology, Faculty of medicine, Zagazig University. Dalia Ibrahim Abdel-Aleem, Professor of Physiology, Faculty of Medicine, Zagazig University. Walid Mohamed Sayed Ahmed EL Nagar, Lecturer of Obstetrics and Gynaecology, Faculty of Medicine - Zagazig University, Amira Mokhtar Abd El-Ghany Gobran

\begin{tabular}{|l} 
(Corresponding author), \\
Assistant lecturer of \\
Physiology, Faculty of \\
Medicine, Zagazig University. \\
Corresponding author: \\
drmero.gobran@gmail.com
\end{tabular}

Submit Date 2019-08-08

Revise Date 2019-08-28

Accept Date 2019-09-01
Background: kisspeptin (kiss1) is a hypothalamic neuropeptide, expressed also peripherally in the placental trophoblast, pancreatic cells, liver and adipose tissue suggesting its role in regulating metabolic homeostasis as well as normal fetal implantation and placentation. There are contradictory reports about the circulating and placental levels of kiss1 during preeclampsia in either lean or obese pregnant women.

Aim: This study was designed to evaluate serum and placental kiss1 levels in normotensive non-pregnant, pregnant and preeclamptic females and to detect any potential association of those levels with some homeostatic parameters occurring in these conditions with and without obesity.

Design: This study was conducted on 54 female subjects at the reproductive period. They were divided according to WHO classification of BMI into two equal groups: Group I (lean group with normal BMI $18.50-24.99 \mathrm{~kg} / \mathrm{m}^{2}$ ), and Group II (obese group with BMI 30 - 34.99 $\mathrm{kg} / \mathrm{m})^{2}$, each group was subdivided into: normotensive non-pregnant group, normotensive pregnant group and preeclamptic group.

Moderate degree of preeclampsia was confirmed by presence of proteinuria $(>300 \mathrm{mg} / 24 \mathrm{~h})$ and hypertension $(\geq 150 / 100)$. Placental kiss 1 and serum kiss1, insulin, glucose, lipid profile, TNF- $\alpha$, urea, creatinine and sex hormones levels were measured. BMI and HOMA-IR were calculated in all groups.

Results: Serum and placental kiss1 levels were significantly higher in normotensive pregnant while these levels were significantly lower in preeclamptic than normotensive pregnant groups and this decrease was more pronounced in obese than lean subjects. Kiss 1 negatively correlated with blood pressure, BMI, glucose, insulin, HOMA-IR, TC, TG, LDL, TNF- $\alpha$ and positively correlated with HDL-C, sex hormones.

Conclusion: The decrease in kiss1 levels may play a role in pathogenesis of PE, and may represent a novel link between metabolic disturbance and PE in obese pregnant females since this peptide was correlated with BMI, HOMA-IR, dyslipidemia and TNF- $\alpha$.

Key word: kiss1, preeclampsia, obesity

\section{INTRODUCTION}

$\mathrm{P}$ reeclampsia (PE) is a pregnancy-specific syndrome .It is a leading cause of maternal morbidity and mortality, with a worldwide prevalence of $2-10 \%$. Obesity is a state of chronic, low-grade inflammation and that pro-inflammatory status mediate the 
development of placental ischemia-induced hypertension $^{[1]}$.

Although the primary mechanism of preeclampsia is still unknown, it is characterized by impaired placental function, abnormal trophoblast invasion, deficient physiologic maternal spiral artery modification, increased apoptosis of trophoblastic cells and placental ischemia .Interestingly a number of factors have been implicated in trophoblast invasion, such as kisspeptin $^{[2]}$.

Kisspeptin is a peptide encoded by the kiss1 gene, binds to $G$ protein-coupled receptor 54 (GPR54) (kiss1r) ${ }^{[3]}$ Both kiss-1 and kiss-1r mRNA are expressed centrally in the brain, spinal cord, hypothalamus, and peripherally in the placental trophoblast, overies, pancreatic cells, liver and adipose tissue ${ }^{[4]}$.

It was proposed that increase in the total number of trophoblast cells throughout the course of gestation is responsible for the dramatic increase in serum kiss1 levels examined especially in the third trimester Dysregulation of the kiss1may negatively affect the processes of implantation as well as placentation [5]. Also its role in regulating body weight and glucose homeostasis was reported ${ }^{[6]}$.

In preeclamptic women, Ziyaraa et al. ${ }^{[3]}$ found a marked decrease in plasma kiss 1 levels when compared with normotensive pregnant women .In contrast, other investigators showed either no difference ${ }^{[7]}$ in circulating kiss1 levels or a significantly high level in preeclamptic patients when compared with normotensive controls ${ }^{[8]}$. Moreover, several studies have reported elevated Kiss-1 mRNA, protein and kiss1r expression in trophoblasts and preeclamptic placenta ${ }^{[9]}$, while other studies found no difference in placental Kiss1r mRNA and protein expression between healthy and preeclamptic pregnancies. In addition to tissue expression studies, decreased maternal serum kiss 1 levels in early pregnancy have been associated with development of preeclampsia ${ }^{[10]}$.

On the hand, there were contradictory reports about the circulating levels of kiss 1 in obese women. While Kolodziejski et al. ${ }^{[12]}$ found lower kiss1 concentrations in obese women and observed a negative correlation between kiss1 and BMI, Çelik et al. ${ }^{[13]}$ found no significant difference in kiss1 levels in overweight and obese women compared with normal-weight women and observed no correlation between kiss1 and BMI.

This study was designed to evaluate serum and placental kiss1 levels in normotensive non-pregnant, pregnant and preeclamptic females and to detect any potential association of those levels with some homeostatic parameters occurring in these conditions with and without obesity

\section{SUBJECTS AND METHODS}

\section{Subjects :}

This study was a case control study that was conducted on 54 female patients their ages ranging between 20-35 years. They were Chosen from the out-patient clinics and inpatients department of Obstetrics and Gynecology- Zagazig University Hospitals after obtaining the required authorities' permissions .It was done during the period from Novamber 2017 to December 2018. The study design was approved by the Institutional Review Board (IRB) NO.305014-12-2016, Faculty of Medicine, Zagazig University.

Written informed consent was obtained from all participants and the study was approved by the research ethical committee of Faculty of Medicine, Zagazig University. The work has been carried out in accordance with The Code of Ethics of the World Medical Association (Declaration of Helsinki) for studies involving humans. Women included in this study were divided according WHO [13] classification of BMI into two equal groups:

Group I (lean group with normal BMI (18.50$\left.\left.24.99 \mathrm{~kg} / \mathrm{m}^{2}\right)(n=27)\right)$ subdivided into:

Group Ia (normotensive non-pregnant group), Group Ib (normotensive pregnant group) and Group Ic (pregnant preeclamptic group).

Group II (obese group with BMI (30 - 34.99 $\left.\left.\mathrm{kg} / \mathrm{m}^{2}\right)(\mathrm{n}=27)\right)$ subdivided into:

Group IIa (normotensive non-pregnant group), Group IIb (normotensive pregnant group) and Group IIc (pregnant preeclamptic group). 


\section{Inclusion criteria:}

- The preeclamptic women included in the study were considered to have moderate preeclampsia according to the criteria established by the Royal College of Obstetricians and Gynecologists (ACOG) ${ }^{[\mathbf{1 4}]}$ if they have:

$\checkmark$ A systolic blood pressure of $\geq 150 \mathrm{mmHg}$ $\&<160 \mathrm{mmHg}$ and/ or diastolic blood pressure of $\geq 100 \mathrm{mmHg} \&<110 \mathrm{mmHg}$ on two occasions at least 6 hours apart, typically occurring after 20 weeks gestation (no more than 1 week apart)

$\checkmark$ In conjunction with new onset proteinuria of $>300 \mathrm{mg} / 24 \mathrm{~h}$ urine collection or > 1+ on two random sample urine dipsticks at least 6 hours apart (no more than 1 week apart).

- The non-preeclamptic women included in the study were:

$\checkmark$ Non- pregnant women non-lactating who had regular menstrual cycle (28 - 33 days), in the follicular phase of the menstrual cycle and no use of prescription medications (including hormonal contraception) for at least 2 months before the study

$\checkmark$ Pregnant women with gestational age greater than 20 weeks with single pregnancy.

\section{Exclusion criteria:}

冈 Women with comorbidities including metabolic, vascular, and systemic diseases as: diabetes, chronic hypertension, proteinuria or urinary tract infection.

冈 Women who have multiple pregnancies or in labor.

$\otimes$ Patients with severe preeclampsia (BP $\geq$ $160 / 110 \mathrm{mmHg}$ with proteinuria $2.0 \mathrm{~g} / 24$ hours or $\geq+2$ dipsticks in the absence of urinary tract infection).

凶 Patients who have previous bad obstetric history or obstetric complications of the current pregnancy.

\section{Data collection}

All preeclamptic pregnant women were hospitalized, while for the normotensive nonpregnant groups. Samples were collected from out-patient clinics and the normotensive pregnant women during routine antenatal visits after the $20^{\text {th }}$ week gestational age that was derived from the last menstrual period and was corrected according to transabdominal and/or transvaginal ultrasonography if needed.
In all groups blood pressure was measured with the patients in a seated position and with the cuff of the sphygmomanometer at the level of the heart, body weight and height were measured and BMI was calculated by using the formula of $\mathrm{kg} / \mathrm{m} 2$.A urine sample was taken and proteinuria was determined according to the method of Dilena et $\mathbf{a l}^{\left[{ }^{[15]}\right.}$.

A venous blood sample was withdrawn at 9.00 a.m. following overnight fasting. Samples were taken into standard serum tubes, allowed to clot, then serum was separated by centrifugation at $3000 \mathrm{rpm}$ for 15 minutes and stored frozen at $-20{ }^{\circ} \mathrm{C}$ until assayed for: kisspeptin according to (manufacturer instructions), urea according to Kaplan. ${ }^{[16]}$, creatinine according to Murray. ${ }^{[17]}$, insulin according to Temple et al. ${ }^{[18]}$, HDL-C according to Nauck et al $^{[19]}$, triglyceride (TG) according to Fossati. ${ }^{[20]}$, total cholesterol, glucose, estrogen and progesterone according to Tietz. ${ }^{[21]}$. TNF- $\alpha$ according to Fernando et al. ${ }^{[2]}$ LDL was calculated as follows: LDL=TC-HDLC-TG/5 .also, HOMA-IR was calculated as follows insulin $(\mu \mathrm{U} / \mathrm{mL}) \times$ glucose $(\mathrm{mg} / \mathrm{dl}) / 405$.

\section{Tissue sampling:}

The placenta was sampled at the time of delivery then washed by saline; cut into small pieces homogenized in 5-10 ml cold buffer, and then was centrifuged at the speed of 2000-3000 r.p.m. for at 20 minutes. After that the supernatant was removed for assaying the kisspeptin level in the placental tissue according to Cirelli et al ${ }^{[23]}$ method.

\section{Statistical analysis:}

Data were presented as mean $\pm \mathrm{SD}$ Statistical analysis of differences between groups was_determined by a one-way analysis of variance (ANOVA) and the correlations between the parameters were analysed using pearson correlation (r). $P<0.05$ was considered statistically significant. SPSS Version 18.0.0 software package (SPSS Inc. Chicago, IL, USA) was used.

\section{RESULTS}

Serum kiss1 levels were significantly higher in normotensive pregnant groups (Ib\&IIb) than non- pregnant groups (Ia\&IIa) $(\mathrm{P}<0.0001)$. These high levels were 
accompanied by significant high levels of insulin, HOMA-IR, total cholesterol (TC), triglyceride (TG), low density lipoprotein (LDL), high density lipoprotein (HDL), TNF$\alpha$, sex hormones and BMI but serum glucose, urea and creatinine levels were significantly lower (table1\&2) .

Serum kiss1 levels were significantly lower in preeclamptic groups (Ic\&IIc) than normotensive pregnant groups (Ib\&IIb) $(\mathrm{P}<$ $0.0001)$. These low levels were accompanied by significant increase in levels of insulin, HOMA-IR, TC, TG, LDL, TNF- $\alpha$, urea, creatinine in addition to blood pressure and BMI but they were associated with a significant decrease in serum levels of HDL and sex hormones. The previously mentioned changes were more pronounced in obese groups (IIa,IIb,IIc) as compared with lean groups (Ia,Ib,Ic) (table1\&2)

Moreover, in all studied groups, There was a significant negative correlation $(\mathrm{P}<0.05)$ between serum kiss1 level and BMI , serum glucose, insulin ,HOMA-IR , total cholesterol, TG, LDL,TNF- $\alpha$ \& blood pressure, while there was a significant positive correlation $(\mathrm{P}<0.05)$ between serum kiss1 levels and serum levels of HDL-C \&sex hormones (table3).

Regarding placental levels of kiss1, there was a significant decrease $(p<0.0001)$ in its levels in lean preeclamptic females as compared to lean normotensive pregnant groups, furthermore this decrease was more pronounced in obese preeclamptic groups (figure

Table (1): Clinical and laboratory data of all studied groups

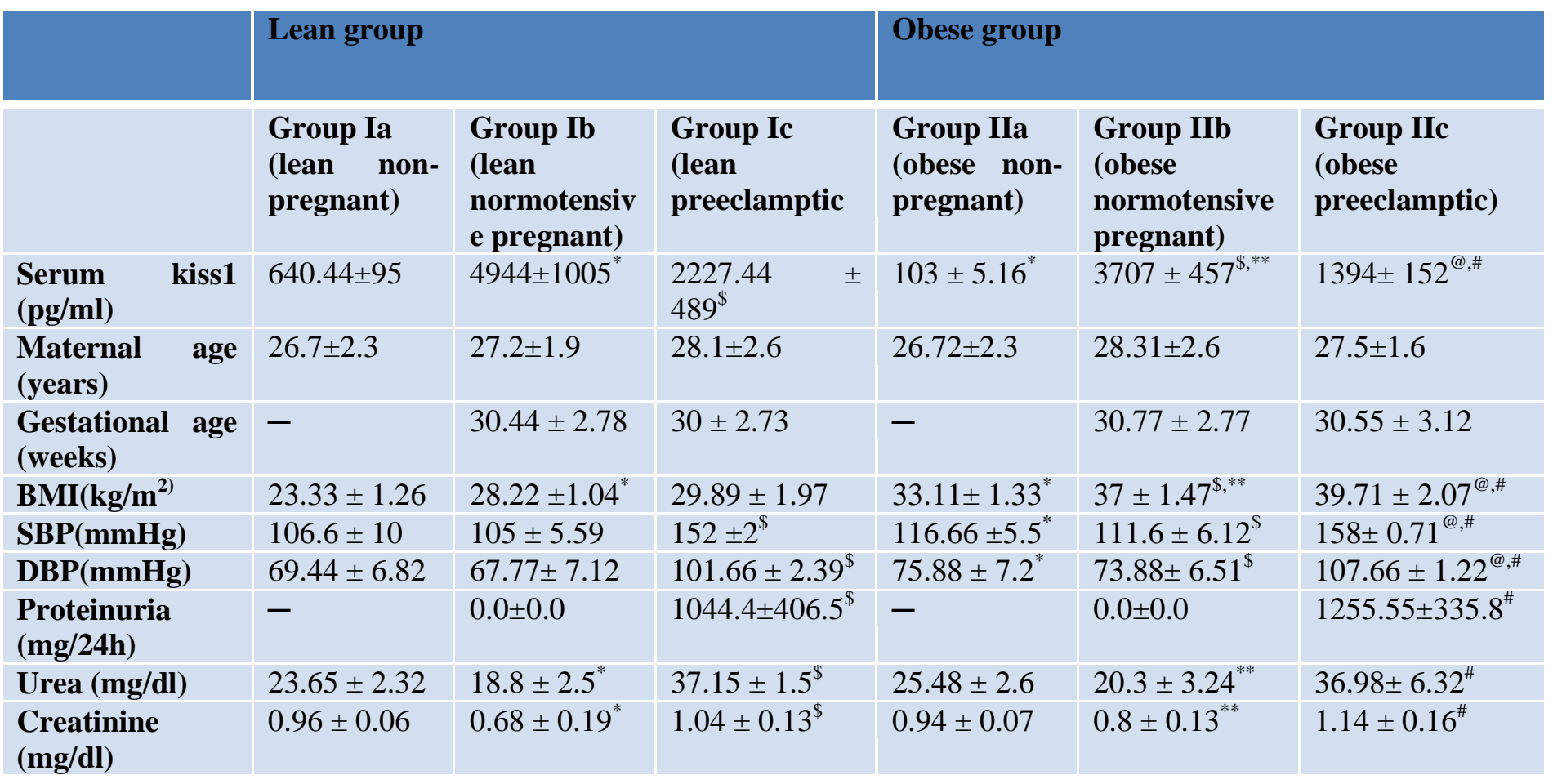

*=Significant vs Ia $\$=$ Significant vs Ib $@=$ Significant vs Ic $\quad * *=$ Significant vs IIa \#= Significant vs IIb

Kiss1 (kisspeptin), SBP (systolic blood pressure), DBP (diastolic blood pressure), BMI (body mass index) . 
Table (2): The mean value \pm SD of metabolic, inflammatory and hormonal parameters measured in all studied groups

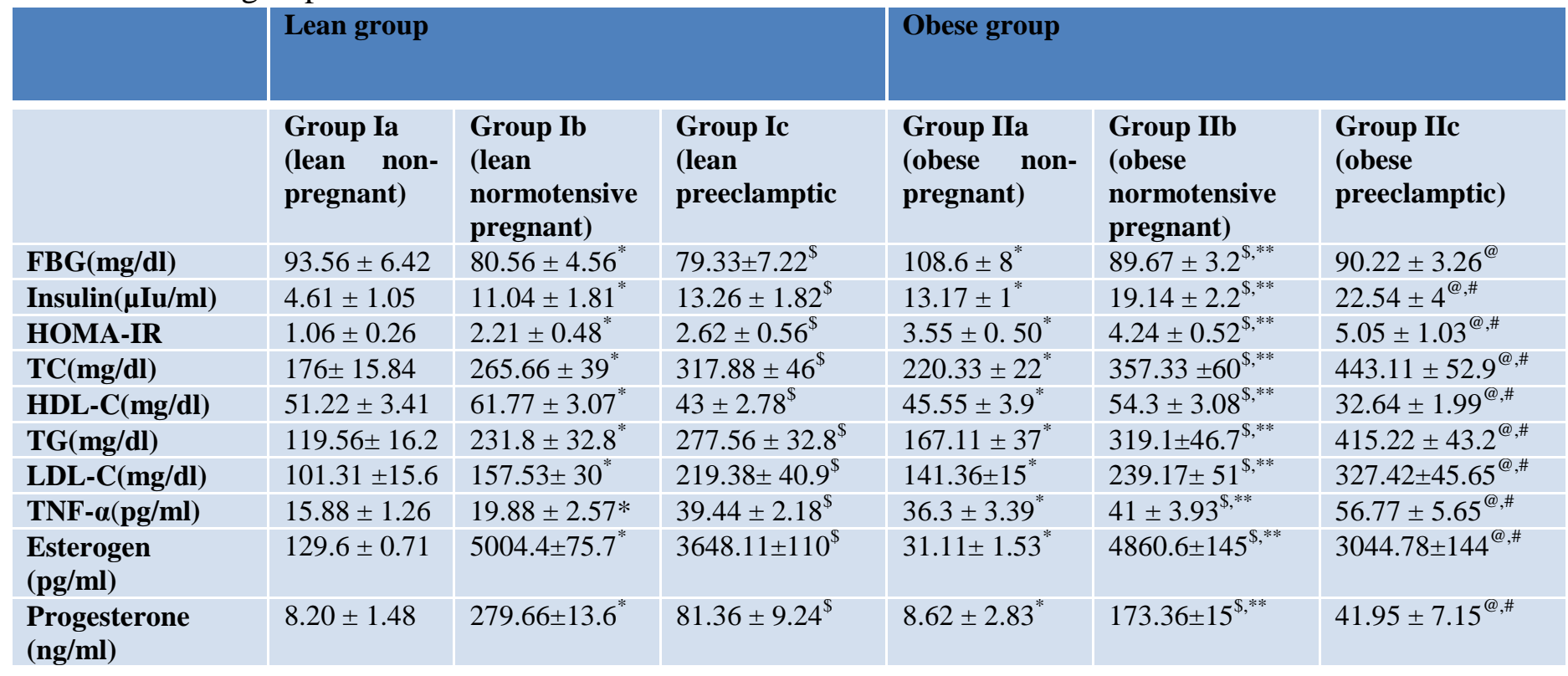

*=Significant vs Ia $\$=$ Significant vs Ib $\quad @=$ Significant vs Ic $\quad * *=$ Significant vs IIa \#= Significant vs IIb

FBG (fasting blood glucose level), TC (total cholesterol), HDL-C (high density lipoproteincholesterol), TG (triglyceride) LDL-C (low density lipoprotein- cholesterol), TNF- $\alpha$ (tumor necrosis factor alpha)

Table (3): Correlation between serum kiss1 levels and all studied parameters in all groups

\begin{tabular}{|c|c|c|c|c|c|c|}
\hline & \multicolumn{3}{|l|}{ Lean group } & \multicolumn{3}{|l|}{ Obese group } \\
\hline & $\begin{array}{l}\text { Group Ia } \\
\text { (lean non- } \\
\text { pregnant) }\end{array}$ & $\begin{array}{l}\text { Group Ib } \\
\text { (lean } \\
\text { normotensiv } \\
\text { e pregnant) }\end{array}$ & $\begin{array}{l}\text { Group Ic } \\
\text { (lean } \\
\text { preeclamp } \\
\text { tic }\end{array}$ & $\begin{array}{l}\text { Group IIa } \\
\text { (obese non- } \\
\text { pregnant) }\end{array}$ & $\begin{array}{l}\text { Group IIb } \\
\text { (obese } \\
\text { normotensiv } \\
\text { e pregnant) }\end{array}$ & $\begin{array}{l}\text { Group IIc } \\
\text { (obese } \\
\text { preeclampti } \\
\text { c) }\end{array}$ \\
\hline & $\mathbf{r}$ & $\mathbf{r}$ & $\mathbf{r}$ & $\mathbf{r}$ & $\mathbf{r}$ & $\mathbf{r}$ \\
\hline BMI & $-0.795^{*}$ & $-0.900 * *$ & $-0.904 * *$ & $-0.943 * *$ & $-0.797 *$ & $-0.977 * *$ \\
\hline SBP & $-0.903 * *$ & $-0.804 * *$ & $-0.712^{*}$ & $-0.680^{*}$ & $-0.849 * *$ & $-0.927 * *$ \\
\hline DBP & $-0.920 * *$ & $-0.919 * *$ & $-0.797 *$ & $-0.842 * *$ & $-0.723^{*}$ & $-0.898 * *$ \\
\hline Urea & -0.053 & -0.122 & 0.394 & -0.559 & 0.402 & -0.044 \\
\hline Creatinine & -0.228 & 0.439 & 0.122 & -0.026 & 0.372 & -0.399 \\
\hline FBG & $-0.824 * *$ & $-0.970 * *$ & $-0.832 * *$ & $-0.992 * *$ & $-0.937 * *$ & $-0.953 * *$ \\
\hline Insulin & $-0.964 * *$ & $-0.939 * *$ & $-0.822 * *$ & $-0.898 * *$ & $-0.681^{*}$ & $-0.683^{*}$ \\
\hline HOMA-IR & $-0.906^{* *}$ & $-0.965 * *$ & $-0.906 * *$ & $-0.975^{* *}$ & $-0.701^{*}$ & $-0.917 * *$ \\
\hline TC & $-0.924 * *$ & $-0.925^{* *}$ & $-0.888 * *$ & $-0.962 * *$ & $-0.951 * *$ & $-0.993 * *$ \\
\hline HDL-C & $0.958 * *$ & $0.947 * *$ & $0.858 * *$ & $0.920 * *$ & $0.972 * *$ & $0.915^{* *}$ \\
\hline TG & $-0.890 * *$ & $-0.844^{* *}$ & $-0.901 * *$ & $-0.976 * *$ & $-0.907 * *$ & $-0.943 * *$ \\
\hline LDL-C & $-0.934 * *$ & $-0.940 * *$ & $-0.779 *$ & $-0.840 * *$ & $-0.890 * *$ & $-0.989 * *$ \\
\hline TNF- $\alpha$ & $-0.833 * *$ & $-0.917 * *$ & $-0.833 * *$ & $-0.925 * *$ & $-0.984 * *$ & $-0.905^{* *}$ \\
\hline Esterogen & $0.873 * *$ & $0.880 * *$ & $0.866 * *$ & $0.878 * *$ & $0.947 * *$ & $0.914 * *$ \\
\hline Progesterone & $0.967 * *$ & $0.912 * *$ & $0.849 * *$ & $0.923 * *$ & $0.955^{* *}$ & $0.819 * *$ \\
\hline
\end{tabular}

r: correlation coefficient *:correlation is significant at $\mathbf{p}<0.05 * *$ :correlation is significant at $\mathbf{p}<0.01$ 


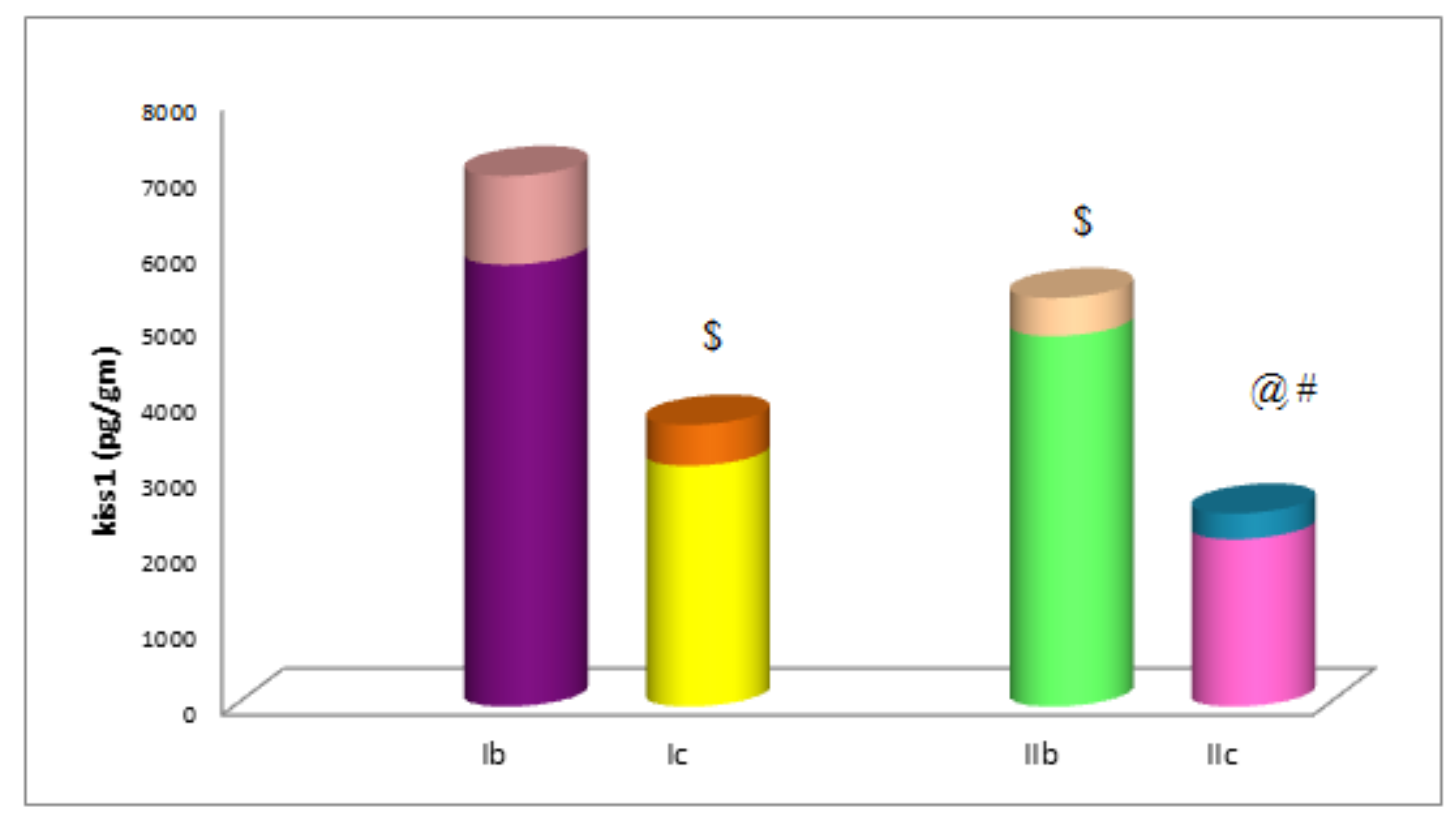

Figure (1): Placental kiss1 levels (pg/gm of tissue) in normotensive pregnant and preecalmptic groups

$$
\$=\text { Significant vs Ib @ @ =Significant vs Ic \#= Significant vs IIb }
$$

\section{DISCUSSION}

This study was designed to evaluate serum and placental kiss1 levels in normotensive non-pregnant, pregnant and preeclamptic females and to detect any potential association of those levels with some homeostatic parameters occurring in these conditions with and without obesity

Regarding serum kiss1, there was a significant increase in its levels in pregnant groups (Ib \&IIb) compared with nonpregnant groups (Ia \&IIa). However, these levels were significantly decreased in preeclamptic groups (Ic \&IIc) as compared to normotensive- pregnant groups.

Our results can be explained by those of Hu et al. ${ }^{[4]}$ who reported that increased total number of trophoblast cells throughout the course of gestation is responsible for the dramatic increase in serum kiss1 levels examined .Also, they concluded that dysregulation of the kiss1 system may negatively affect the processes of implantation as well as placentation. This notion supports our results of decreased serum kiss1 levels in preeclamptic groups. Moreover, other investigators reported marked decrease of plasma kiss1 in PE patients when compared with normotensive controls $^{[3,9]}$.Furthermore $\mathbf{W u}$ et al. ${ }^{[24]}$ suggested that kiss1 may modulate embryo implantation and decidual programming in human pregnancy via the focal adhesion kinase (FAK)-steroid receptor coactivator intracellular tyrosine kinases pathway.

In contrast to these data, Nijher et al. ${ }^{[6]}$ did not find any difference in circulating kiss1 levels between preeclamptic women and trimester-matched normotensive controls, while Vazquez-Alaniz et al. ${ }^{[7]}$ reported high levels of kiss in preeclampsia patients.

Furthermore in the present work, there was a significant decrease in serum and placental kiss1levels in obese groups as compared to that of lean groups. There was also a significant negative correlation between serum kiss1level and BMI in all studied groups. These findings are in agreement with Kolodziejski et al ${ }^{[11]}$ who found lower kiss1 concentrations in obese women compared to lean and observed a negative correlation between kiss1 and BMI. In addition, Logie et al. ${ }^{[25]}$ demonstrated that plasma kiss1 levels were significantly lower in obese pregnant compared with lean pregnant women. In contrast to our results, some investegators 
found no significant difference in kiss1 levels in overweight and obese females compared with normal-weight females. Also, observed no correlation between circulating kiss1 levels and $\mathrm{BMI}{ }^{[12]}$.

In the present study, pregnant women showed significantly higher serum insulin levels and HOMA-IR index when compared with non-pregnant women, while there was a significant decrease in serum blood glucose levels in the same group.

As regards lipid profile, our study showed a significant increase in serum levels of total cholesterol, HDL, TG, LDL, VLDL in pregnant groups when compared with nonpregnant groups. These results are supported by many studies that reported higher level of lipid profile in pregnant women ${ }^{[1]}$.

Furthermore, in our study obese subjects (groupIIa,IIb,IIc) showed significantly higher serum levels of glucose and insulin in addition to HOMA-IR index when compared with lean subjects (groupIa,Ib,Ic). Moreover, the levels of serum TC, TG and LDL were significantly increased, while, there was a significant decrease in HDL levels in the same group. These results are in line with those of Scifres et al. ${ }^{[26]}$ who found that overweight/obese women have significantly more atherogenic lipid profiles than normal weight women and observed that in all types of hyperlipidemia, there was lowering of insulin sensitivity.

Decreased serum kiss1 levels encountered in the present study may play a crucial role in the metabolic alterations linking obesity via changes in IR, lipid profile and adipocytokine. Our results showed a significant negative correlation between serum kiss1 level and serum levels of glucose, insulin and HOMA-IR in all groups. These results are in accordance with those of other investigators who explored the negative associations between kiss1 levels and obesity, dyslipidemia $\& \mathrm{IR}^{[11]}$.

Insulin resistance is one of the major causes of dyslipidemia .Our results showed a significant negative correlation between serum kiss1 level and serum levels of TC, TG, LDL in all groups, while there was a significant positive correlation between serum kiss1 and HDL levels in all studied groups. Kolodziejski et al. ${ }^{[11]}$ found negative correlation between kiss1 and leptin and a positive one with adiponectin as determinants of insulin resistance and obesity. leptin has a pro-inflammatory activity and increases IR while adiponectin has reversed effect.

The results of the present study showed non-significant changes in systolic and diastolic blood pressure in pregnant groups as compared with non-pregnant groups. However, blood pressure was significantly higher in preelamptic groups as compared with pregnant and in obese groups when compared with non-obese groups. A significant negative correlation between kiss1 and systolic \& diastolic blood pressure were found in all groups. These finding are in line with those of Logie et al. ${ }^{[25]}$ who found strong negative associations between circulating kiss1 in pregnancy and blood pressure. Our results are also supported by those of Bedenbaugh et al. ${ }^{[27]}$ who reported that NO release may be influenced directly by kiss1. Moreover, Mezei et al. ${ }^{[28]}$ suggested that kiss 1, through the alteration of eicosanoid synthesis in platelets and aorta, may play a role in the regulation of vascular tone.

The results in the present work revealed significant increase in serum levels of estrogen and progesterone in pregnant groups (Ib\&IIb) when compared with non-pregnant groups (Ia\&IIa) .However, their levels were significantly decreased in preelamptic groups as compared with pregnant and in obese groups when compared with non-obese groups. Furthermore, there was a significant positive correlation between kiss1 and estrogen \& progesterone in all groups. This is in agreement with the results of other studies $^{[29]}$.

In the present study, there was a significant increase in serum level of TNF- $\alpha$ in pregnant groups (Ib\&IIb) when compared with non- pregnant groups (Ia\&IIa).Moreover this increase was more profound in obese preeclamptic women than other groups and there was a negative significant correlation between kiss 1 and TNF- $\alpha$ in all groups These results are in accordance with those of other studies that found elevated maternal 
circulating TNF- $\alpha$ and IL-6 levels with high predictive values for preeclampsia ${ }^{22]}$ However, these findings are in contrast to those of Afshari et al. ${ }^{[30]}$ who showed that serum TNF- $\alpha$ level was not associated with preeclampsia.

Kiss1 and Kiss1r mRNAs have been detected in the peripheral blood leukocytes and lymphocytes. Moreover, kiss1/kiss1r efficiently suppressed the activation of PI3 kinase (PI3K)-Akt pathway by receptor tyrosine kinases (RTKs), resulting in the inhibition of cytokines. The reverse will occur when circulating kiss 1 levels are decreased as observed in obese and preeclamptic women of the present study and other studies ${ }^{[31]}$. Therefore, reduction in circulating kiss1 levels may be a cause or a result of the inflammatory process encountered in obesity and PE

Conclusion: The present study revealed that placental and serum kiss1 levels were significantly increased during normal uncomplicated pregnancy while significantly decreased during pregnancy complicated with $\mathrm{PE}$ either in lean or obese women, however, this decrease was more exaggerated in obese. Moreover, kiss1 may play a role in pathogenesis of $\mathrm{PE}$ and its associated metabolic, hormonal and proinflammatory changes.

Recommendation: Further studies are required to clarify the possible benefit of using kiss1 and/or anti-TNF $\alpha$ treatment in PE.

No conflict of interest.

No financial disclosure.

\section{REFERENCES}

1) Li Y, He J, Zeng $X$, Zhao S, Wang $X$, Yuan H .Non-fasting lipids detection and their significance in pregnant women. Lipids in health and disease 2019; 18(1): 96.

2) Rana S, Lemoine E, Granger J, Karumanchi S A. Preeclampsia: pathophysiology, challenges, and perspectives. Circulation research 2019; 124 (7): 1094-1112.

3) Ziyaraa M A, Hamdan F B, Mousa L R. Correlation of Kisspeptin-10 level and fetal well-being in preeclamptic patients. Taiwanese Journal of Obstetrics and Gynecology 2016; 55(6): 840-846.

4) Hu K L, Chang H M, Zhao H C, Yu Y, Li R, Qiao J. Potential roles for the kisspeptin/kisspeptin receptor system in implantation and placentation. Human reproduction update 2019; 25(3): 326-343.

5) Tolson K P, Garcia C, Yen S, Simonds S, Stefanidis A, Lawrence A, Kauffman A S . Impaired kisspeptin signaling decreases metabolism and promotes glucose intolerance and obesity. The Journal of clinical investigation 2014; 124(7): 3075-3079.

6) Nijher G M, Chaudhri O B, Ramachandran R, Murphy K G, Zac-Varghese S E, Fowler A, et al. The effects of kisspeptin-54 on blood pressure in humans and plasma kisspeptin concentrations in hypertensive diseases of pregnancy. British journal of clinical pharmacology, 2010; 70(5): 674-681.

7) Vazquez-Alaniz F, Galaviz-Hernandez C, Marchat L A, Salas-Pacheco J M, Chairez-Hernandez I, Guijarro-Bustillos J J, et al. Comparative expression profiles for KiSS-1 and REN genes in preeclamptic and healthy placental tissues. European Journal of Obstetrics \& Gynecology and Reproductive Biology 2011; 159(1): 67-71.

8) Cartwright J E and Williams P J. Altered placental expression of kisspeptin and its receptor in preeclampsia. The Journal of endocrinology 2012; 214(1): 79.

9) Ćetković A, Miljic D, Ljubić A, Patterson M, Ghatei M, Stamenković J, et al. Plasma kisspeptin levels in pregnancies with diabetes and hypertensive disease as a potential marker of placental dysfunction and adverse perinatal outcome. Endocrine research 2012; 37(2): 78-88.

10)Qiao C, Wang C, Zhao J, Liu C, Shang T. Elevated expression of KiSS-1 in placenta of Chinese women with early-onset preeclampsia. PLoS One 2012; 7(11): e48937.

11)Kołodziejski P A, Pruszyńska-Oszmałek E, Korek E, Sassek M, Szczepankiewicz D, Kaczmarek P, et al . Serum levels of spexin and kisspeptin negatively correlate with obesity and insulin resistance in women. Physiological research 2018; 67(1): 45-56.

12)Çelik F, Belviranli M, Okudan N. Circulating levels of leptin, nesfatin-1 and kisspeptin in postmenopausal obese women. Archives of physiology and biochemistry 2016; 122(4): 195199.

13) World Health Organization. Retrieved 15 February 2014 .BMI classification.

14) ACOG. Hypertension in pregnancy. Report of the American College of Obstetricians and Gynecologists' Task Force on Hypertension in Pregnancy. Journal of Obstetrics \& Gynecology. 2013; 122 (5): 1122-1131

15)Dilena B A, Penberthy L A, Fraser C G. Six methods for determining urinary protein compared. Clinical chemistry 1983;29(3): 553557.

16)Kaplan A. Urea Kaplan A. et al. Clin Chem the C.V. Mosby Co. St Louis. Toronto. Princeton. 1984; 1257- 1260 and 437 and 418. 
17)Murray RL. Non-protein compounds, in: Kaplan LA and Pesce AJ (editors), Clinical chemistry: Theory, analysis and co-relation, Mosby CV Toranto, 1984; 1230-68.

18) Temple R, Clark P M S, Hales C N. Measurement of insulin secretion in type 2 diabetes: problems and pitfalls. Diabetic medicine 1992; 9(6): 503512.

19) Nauck M, März W, Jarausch J, Cobbaert, C, Sägers, A, Bernard D, et al. Multicenter evaluation of a homogeneous assay for HDL-cholesterol without sample pretreatment. Clinical chemistry 1997; 43(9): 1622-1629.

20)Fossati P. Princepel Lab. Clinical chemistry 1982; 28:2077-2079.

21)Tietz NW . Clinical guide to laboratory tests. Philadelphia: WB Saunders 1995; 268:273-5.

22)Fernando B, Marley R, Holt S, Anand R, Harry D, Sanderson $\mathrm{P}$, et al. N-acetylcysteine prevents development of the hyperdynamic circulation in the portal hypertensive rat. Hepatology, 1998;28(3): 689-694.

23)Cirelli N, Lebrun P, Gueuning C, Moens A, Delogne-Desnoeck J, Dictus-Vermeulen C, et al. Secretory characteristics and viability of human term placental tissue after overnight cold preservation. Human reproduction 2000; 15(4): 756-761.

24)Wu H M, Huang H Y, Soong Y K, Leung P K, Wang $\mathrm{H}$ S. Kisspeptin regulation of human decidual stromal cells motility via FAK-Src intracellular tyrosine kinases. Human Reproduction 2019.

25)Logie J J, Denison F C, Riley S C, Ramaesh T, Forbes S, Norman $\mathbf{J}$ E, et al. Evaluation of kisspeptin levels in obese pregnancy as a biomarker for pre-eclampsia. Clinical endocrinology 2012; 76(6): 887-893.

26)Scifres C M, Catov J M, Simhan H N. The impact of maternal obesity and gestational weight gain on early and mid-pregnancy lipid profiles. Obesity 2014; 22(3): 932-938.

27)Bedenbaugh M N, Richard B, McCosh J A, Lopez J M, Connors R L, Goodman S M, et al. Neuroanatomical Relationship of Neuronal Nitric Oxide Synthase to Gonadotropin-Releasing Hormone and Kisspeptin Neurons in Adult Female Sheep and Primates. Neuroendocrinology 2018;107:218-227

28)Mezei Z, Zamani-Forooshani, O, Csabafi K, Szikszai B, Papp E, Ónodi, Á, et al. The effect of kisspeptin on the regulation of vascular tone. Canadian journal of physiology and pharmacology 2015; 93(9): 787-791.

29)Panidis D, Rousso D, Koliakos G, Kourtis A, Katsikis I, Farmakiotis D, et al. Plasma metastin levels are negatively correlated with insulin resistance and free androgens in women with polycystic ovary syndrome. Fertility and sterility 2006; 85(6): 1778-1783.

30) Afshari J T, Ghomian N, Shameli A, Shakeri M T, Fahmidehkar M A, Mahajer E, et al. Determination of Interleukin-6 and Tumor Necrosis Factor-alpha concentrations in Iranian-Khorasanian patients with preeclampsia. BMC pregnancy and Childbirth 2005; 5(1): 14.

31)Navenot J M, Fujii N, Peiper S C. KiSS1 metastasis suppressor gene product induces suppression of tyrosine kinase receptor signaling to Akt, tumor necrosis factor family ligand expression, and apoptosis. Molecular pharmacology 2009; $\quad$ 75(5): $\quad$ 1074-1083.

\section{HOW TO CITE}

asalah, A., El-Sayed, M., Abdel-Aleem, D., EL Nagar, W., Gobran, A. Serum Kisspeptin Level in normal pregnancy and preeclampsia with and without obesity. Zagazig University Medical Journal, 2021;2 (343351): -. doi: 10.21608/zumj.2019.15804.1416 